\title{
O papel da extensão universitária no contexto da pandemia de COVID-19 para famílias com crianças e adolescentes portadores de doença falciforme: relato de experiência
}

The role of university extension in the context of the COVID-19 pandemic for families of children and adolescents with sickle cell disease: an experience report

La actuación de la extensión universitaria en el contexto de la pandemia por COVID-19 para familias con niños y adolescentes con la enfermedad falciforme: relato de experiencia

Recebido: 19/08/2021 | Revisado: 29/08/2021 | Aceito: 02/09/2021 | Publicado: 05/09/2021

Luiza Gabriela Noronha Santiago ORCID: https://orcid.org/0000-0001-8467-072X Universidade Federal de São João Del-Rei, Brasil

E-mail: luizagnoronhas@gmail.com

Elaine Cristina Rodrigues Gesteira ORCID: https://orcid.org/0000-0002-9153-5777 Universidade Federal de São João Del-Rei, Brasil E-mail: elaine_gesteira@ufsj.edu.br

Charlene Regina da Cruz

ORCID: https://orcid.org/0000-0002-7974-8083 Universidade Federal de São João Del-Rei, Brasil E-mail: charlenebio@aluno.ufsj.edu.br

Larissa Mirelly Mendes Carvalho ORCID: https://orcid.org/0000-0002-7824-4975 Universidade Federal de São João Del-Rei, Brasil E-mail: larissamirelly152@gmail.com

Letícia Camilo Santos

ORCID: https://orcid.org/0000-0002-9113-7453 Universidade Federal de São João Del-Rei, Brasil

E-mail: leticiacamilosantos2012@gmail.com

Nicolle Fraga Coelho

ORCID: https://orcid.org/0000-0001-8586-5916 Universidade Federal de São João Del-Rei, Brasil E-mail: nicolle.fcoelho@hotmail.com

Nely Fernandes Xavier Correia ORCID: https://orcid.org/0000-0003-4411-5427 Universidade Federal de São João Del-Rei, Brasil E-mail: nellycorreia4@gmail.com

Thayane Ingrid Xavier de Andrade ORCID: https://orcid.org/0000-0002-6561-7509 Universidade Federal de São João Del-Rei, Brasil E-mail: thatha.red@gmail.com

Patrícia Peres de Oliveira

ORCID: https://orcid.org/0000-0002-3025-5034 Universidade Federal de São João Del-Rei, Brasil E-mail: pperesoliveira@ufsj.edu.br

Edilene Aparecida Araújo da Silveira ORCID: https://orcid.org/0000-0001-7378-2240 Universidade Federal de São João Del-Rei, Brasil E-mail: edileneap@ufsj.edu.br

Vanessa Faria Cortes ORCID: https://orcid.org/0000-0002-6464-7634 Universidade Federal de São João Del-Rei, Brasil E-mail: cortesvf@gmail.com.br

Walquíria Jesusmara dos Santos ORCID: https://orcid.org/0000-0002-1729-141X Universidade Federal de São João Del-Rei, Brasil E-mail: waljsantos@ufsj.edu.br 


\begin{abstract}
Resumo
Doença Falciforme (DF) é a nomenclatura utilizada para designar um conjunto de hemoglobinopatias decorrentes de uma mutação no gene beta-globina do cromossomo 11. Dentre elas, destaca-se a anemia falciforme (HbSS) pela sua alta prevalência e alto potencial de morbimortalidade. Nesse cenário, uma família que apresenta uma criança ou adolescente com DF tem alterada toda sua dinâmica biopsicossocial, sobretudo no contexto da pandemia do COVID19, na qual o distanciamento social é recomendado. Assim, esse trabalho visa apresentar a experiência bem-sucedida do Programa Extensionista "Educar Falciforme", vinculado à Universidade Federal de São João Del-Rei, pilar na rede de apoio para o manejo do cliente e da família com DF, em um período em que novos processos - sobretudo online tornam-se necessários para a oferta de cuidados em saúde de doenças crônicas não transmissíveis (DCNT). Como metodologia, o relato de experiência e a pesquisa bibliográfica foram propostos. A partir dessa experiência, os resultados apontaram que apesar das circunstâncias adversas, as dinâmicas virtuais são necessárias para a manutenção da integralidade do cuidado das famílias com DF em um período pandêmico. Concluiu-se que a extensão é uma ferramenta importante para o apoio na rede de saúde.
\end{abstract}

Palavras-chave: Educação em saúde; Doença falciforme; COVID-19; Cuidado da criança; Saúde da família.

\begin{abstract}
Sickle Cell Disease (SCD) is the nomenclature used to designate a set of hemoglobinopathies resulting from a mutation in the beta-globin gene on chromosome 11. Among them, sickle cell anemia (HbSS) stands out for its high prevalence and high potential for morbidity and mortality. In this scenario, a family with a child or adolescent with SCD changes its biopsychosocial dynamic entirely, especially in the context of the COVID-19 pandemic, in which social distancing is recommended. This work intend to present the successful experience of the Extension Program "Educar Falciforme", linked to the Federal University of São João Del-Rei, a pillar in the support network for the management of patients and families with SDC, in a period that new processes, especially online, became necessary for the provision of healthcare for chronic non-communicable diseases (NCDs). The experience report and the bibliographical research were proposed as a methodology. Based on this experience, the results showed that despite adverse circumstances, virtual dynamics are necessary to maintain comprehensive care for families with SCD in a pandemic period. It is concluded that the extension is an important tool for support in the health community network.
\end{abstract}

Keywords: Health education; Sickle cell disease; COVID-19; Child care; Family health.

\title{
Resumen
}

La enfermedad falciforme es la nomenclatura utilizada para designar el conjunto de hemoglobinopatías resultantes de una mutación en el gen de beta globina en el cromosoma 11. La más relevante de ella es la anemia de células falciformes debido a su alta prevalencia y alto potencial de morbimortalidad. En este escenario, una familia con un niño o adolescente con la enfermedad falciforme tiene que cambiar toda su dinámica psicobiológica, principalmente en el contexto de la pandemia por Coronavirus 19, en que se recomienda el distanciamiento social. Así, este trabajo objetiva presentar la experiencia exitosa del Programa de extensión "Educar Falciforme", vinculado a la Universidad Federal de São João Del Rei, un pilar en la red de apoyo para el manejo de pacientes y familias con enfermedad falciforme, en un período en qué nuevos procesos, especialmente en línea, se vuelven necesarios para la promoción de la atención médica para las enfermedades crónicas no transmisibles (ENT). Como metodología se propuso el relato de experiencia y la búsqueda bibliográfica. Con base en esta experiencia, los resultados mostraron que a pesar de las tribulaciones, las interacciones virtuales son necesarias para mantener una atención integral a las familias con enfermedad falciforme en un período pandémico. Se concluyó que la extensión es una herramienta importante de apoyo a la red de salud.

Palabras clave: Educación en salud; Anemia de células falciformes; COVID-19; Cuidado del niño; Salud de la familia.

\section{Introdução}

Doença Falciforme (DF) é a nomenclatura utilizada para designar um conjunto de hemoglobinopatias decorrentes de uma mutação no gene beta-globina do cromossomo 11, onde um aminoácido de ácido glutâmico é substituído pelo aminoácido valina (Chakravorty \& Williams, 2015). Essa alteração da molécula de DNA modifica a estrutura bicôncava da hemoglobina normal (HbA). Em seu novo formato, a hemoglobina expressa ao menos um alelo S, tornando-se HbS. A letra "S" advém do inglês sickle - foice, em tradução para o português (Almeida \& Beretta, 2017). A modificação da estrutura molecular da hemoglobina confere a ela uma polimerização anormal culminando em um formato de foice à hemácia, motivo pelo qual a doença é nomeada. Situações adversas como baixos níveis de oxigênio, baixas temperaturas e estresse são fatores precipitantes ao processo de falcização (Chakravorty \& Williams, 2015; Piel \& Steinberg, 2017). 
Dentre os genótipos que contemplam a DF, destaca-se a anemia falciforme (HbSS) pelo seu alto potencial de morbimortalidade, em que o quadro clínico é mais agressivo quando comparado às outras hemoglobinopatias falciformes, como as HbSC, HbSD e HbS-beta-talassemia (Zago \& Pinto, 2007; Chakravorty \& Williams, 2015; Almeida \& Beretta, 2017). A sua origem decorre de um padrão de herança autossômico recessivo, isto é, os progenitores de um indivíduo portador de anemia falciforme devem ser doentes ou portar, cada um, um único alelo mutado, o que confere ao sujeito o chamado "traço falciforme" (HbAS). Portadores do traço falciforme em geral são assintomáticos ou cursam sem manifestações clínicas importantes, todavia podem transmitir o gene mutado aos seus descendentes, de modo que o aconselhamento genético e o planejamento familiar é uma premissa importante para a população afetada (Giovelli et al., 2011; Rosenfeld et al., 2019; Ramos et al., 2020).

A anemia falciforme está entre as doenças de origem genética monogênica mais prevalentes do mundo, sendo intimamente associada à população de origem afrodescendente, tendo em vista a sua origem que remete ao continente Africano e à região do mediterrâneo (BRASIL. Ministério da Saúde, 2015). No Brasil, o estado da Bahia apresenta a maior incidência da doença, em segundo lugar está o Rio de Janeiro, seguido pelos estados do Maranhão, Pernambuco, Minas Gerais e Goiás em proporção muito semelhante. (Rosenfeld et al., 2019; Ramos et al., 2020). De modo geral, os estados do Norte e Nordeste contemplam a maior parte dos indivíduos portadores de DF, regiões com maior percentual de indivíduos autodeclarados pretos e pardos. (Cançado \& Jesus, 2007; Rosenfeld et al., 2019).

A fisiopatologia da doença está associada ao formato falciforme das hemácias, responsável por suscitar um processo de vaso-oclusão vascular, com consequente ativação de células endoteliais, processos inflamatórios intravasculares disseminados e da cascata de coagulação, que por sua vez realimenta o processo de micro-oclusão (feedback positivo) e contribui para a isquemia tecidual. O processo de hemólise também se altera e impacta diretamente a circulação sanguínea de oxigênio: a vida útil das hemácias dos indivíduos acometidos dura cerca de 10 dias - em contraste aos 120 dias para indivíduos saudáveis. Crise álgica é a manifestação clínica mais importante nesse contexto de má perfusão, com potencial de internação hospitalar e necessidade de intervenções recorrentes como a oxigenioterapia e a hemotransfusão (Chakravorty \& Williams, 2015; Piel \& Steinberg, 2017; Ramos et al., 2020).

Diante do exposto, uma família que apresenta uma criança ou adolescente com DF tem alterada toda sua dinâmica biopsicossocial. A patologia em si acarreta um estresse intrínseco em um cenário permeado por incertezas, inseguranças, angústias, ansiedade e baixo apoio comunitário (Figueiredo et al., 2018). Deve-se considerar a base familiar como um importante pilar na rede de apoio desse público, sendo o estresse e a ansiedade parental, variáveis emocionais negativas no controle e enfrentamento da DF, visto que os pais tendem a diminuir os recursos de tempo, atenção e cuidado para o progenitor em detrimento do seu próprio adoecimento mental e capacidade funcional (Caprini et al., 2020; Gesteira et al., 2020). Somado a isso, com o advento da pandemia da COVID-19, essa população demanda ainda mais cuidado, uma vez que a infecção pelo Sars-CoV-2 é recente e carece de estudos e dados para se determinar os potenciais riscos da sua gravidade nessa população (Elia et al., 2021). A literatura tem demonstrado concomitância da infecção por Sars-CoV-2 com quadros de crises vasooclusivas e/ou de síndrome torácica aguda (Vilela et al., 2021).

No contexto da necessidade de cuidado multidisciplinar associado à DF, o programa de extensão universitária mostrase como uma ferramenta de intervenção em saúde que integraliza diversas áreas em prol do bem-estar da comunidade. Partindo da premissa de que a universidade é uma instituição social, a educação não deve ser cerceada a ela, de modo que o conhecimento deve ser democratizado (Santos et al., 2016). A extensão universitária promove, justamente, um elo entre comunidade e universidade, propiciando pesquisa e aprendizado sobre uma determinada área a fim de responder às necessidades e promover melhorias na sociedade (Pinotti, 2020; Mélo et al., 2021). 
Este trabalho visa descrever as ações executadas pelo Programa Extensionista Educar Falciforme, vinculado ao Programa Institucional de Bolsas de Extensão - Pibex da Universidade Federal de São João Del-Rei - Campus Centro-Oeste, no contexto da pandemia da COVID-19, a qual modificou a dinâmica das atividades presenciais. Assim, os recursos e as intervenções utilizadas pelo Programa foram adaptados para a manutenção do cuidado às famílias de crianças e adolescentes com DF nesse período de isolamento social preconizado pelos órgãos de saúde pública.

\section{Metodologia}

Trata-se de um relato de experiência (RE), estudo que propõe descrever as características de um determinado grupo ou fenômeno social, levantando subsídios para pormenorizar as relações entre os sujeitos em uma determinada situação. Conforme descrito por Daltro e Faria (2019, p.225) o RE permite a possibilidade de criação de narrativa científica capaz de englobar processos e produções subjetivas, compreendendo que estas não podem ser estritas a fórmulas universais. Nessa perspectiva, o RE tem como finalidade apresentar as fases do estudo, explorando-a como uma concepção teórica pertinente à temática apresentada. Esta é uma ramificação advinda da pesquisa qualitativa, com caráter subjetivo, empírico e que apresenta de forma descritiva a vivência do relator diante de um evento, baseando-se em suas experiências e opiniões políticas, epistemológicas e temporais (Daltro \& Faria, 2019; Souza \& Carvalho, 2021). No contexto de saúde-doença, a RE é essencialmente importante para a avaliação das relações biopsicossociais remanescentes por esse processo devido à singularidade de cada família ao vivenciar uma doença crônica (Gesteira et al., 2020). A pesquisa bibliográfica também foi utilizada com o objetivo de ampliar a discussão no que tange a experiência dos autores.

\subsection{Programa Extensionista Educar Falciforme}

A ação extensionista é desempenhada por oito acadêmicos dos cursos de enfermagem e medicina, previamente capacitados por meio de aulas teóricas e discussões biopsicossociais no contexto familiar de crianças e adolescentes portadores de DF, além de cinco docentes pesquisadoras da condição falciforme nas respectivas áreas de atuação, entre as quais saúde da criança e do adolescente, saúde coletiva, saúde mental, saúde da mulher e em bioquímica/biologia molecular, todas participantes do Programa Educar Falciforme, o qual promove ações educativas para famílias e profissionais de saúde visando o cuidado integral de crianças e adolescentes com DF.

O Programa Educar Falciforme iniciou as suas atividades no primeiro semestre de 2019 na modalidade presencial, com encontros mensais entre docentes e discentes voltados para a capacitação dos membros, discussão de casos e realização de atendimento personalizado às famílias de crianças e adolescentes com DF. Conforme a demanda de cada família, intervenções específicas eram realizadas no âmbito da educação em saúde e da prevenção de complicações advindas da condição, sempre por meio de visitas domiciliares e encontros mensais em grupo com todas as famílias para o acolhimento e escuta ampliada.

No entanto, em março de 2020, com o advento da pandemia da COVID-19, as ações foram executadas na modalidade remota e síncrona, com encontros mensais e orientações individuais para cada núcleo familiar. Com o intuito de assegurar a rede de apoio e como forma de amenizar as adversidades ocasionadas pelo período pandêmico, o Programa continua a realizar o acompanhamento as famílias vinculadas através da plataforma Google Meet. As reuniões têm caráter virtual em decorrência do momento vigente, sendo a primeira realizada em Julho de 2020, com o objetivo de reunir familiares e pessoas com DF, promovendo uma melhor assistência através de um suporte multiprofissional por meio do ambiente virtual de saúde. Nessa nova conjuntura, os acadêmicos também utilizam as redes sociais com exposições de assuntos relacionados ao autocuidado, prevenção da COVID-19 e de agravos próprios da DF, por meio do Facebook e Instagram, criados exclusivamente para o Projeto. 


\section{Resultados e Discussão}

$\mathrm{O}$ contexto atual da pandemia devido ao vírus Sars-coV-2 evidencia ainda mais os aspectos deficitários na rede assistencial em saúde à medida que o acesso ao tratamento com o especialista e a rede de apoio ao cuidado são dificultados em detrimento do isolamento social, provocando a descontinuidade do cuidado, perda de vínculo com o profissional da saúde, com consequências desfavoráveis ao tratamento e à rede de apoio, bem como a baixa satisfação psicoemocional dos clientes acometidos por essa condição crônica. Assim, a atual conjuntura acarreta um misto de sentimentos a toda a população, mas, em se tratando de doentes crônicos, há um aumento das incertezas e o potencial de agravamento da doença (Estrela et al., 2020).

Segundo o Guia de Vigilância Epidemiológicas: emergência de saúde pública de importância nacional pela doença pelo coronavírus 2019 - covid-19, as Doenças Crônicas Não Transmissíveis (DCNT), doenças tais como a anemia falciforme e talassemia são consideradas fatores de risco para agravamento da COVID-19 (Brasil. Ministério da Saúde, 2021). Roy et al. (2020, p.636) destaca ainda o risco aumentado de complicações em caso de diagnósticos errôneos para afecções bacterianas pulmonares, uma vez que apresentam certa similaridade clínica com a infecção por COVID-19. Além disso, aspectos socais tornam-se ainda mais sobressaltos tendo em vista o caráter de vulnerabilidade da maioria dos indivíduos com anemia falciforme (Gustin et al., 2021).

Face do exposto, evidencia-se o impacto da extensão universitária no cuidado em saúde de famílias favorecidas pelo Projeto Educar Falciforme. Em agosto de 2021, 15 famílias de crianças e adolescentes com DF de um município de Minas Gerais compunham o grupo e participavam das reuniões online. No período de Agosto/2020 a Agosto/2021 foram realizadas cinco reuniões, as quais foram previamente definidas em dia e horário conforme demanda da maioria do grupo assistido com o objetivo de fortalecer atualização literária, autocrítica e estímulo cognitivo dos membros em relação à DF, além de oportunizar a troca de experiência entre as partes, oferecer um ambiente de liberdade de fala, entre outros.

Os aspectos dificultadores identificados pelos membros familiares para os encontros virtuais são: dificuldade de acesso à internet; dificuldade de interromper as atividades habituais para participar da reunião; ruídos domésticos que atrapalham a fala e a escuta. Os discentes pontuaram como aspectos negativos: dificuldade de estabelecer vínculos com os indivíduos; dificuldade de reconhecer as necessidades familiares - evidenciadas com notoriedade nas visitas domiciliares; perda de adesão familiar. Contudo, as famílias relatam espontaneamente o sentimento de acolhimento, agradecem a espaço escuta e o apoio, reforçando o impacto positivo das reuniões no que tange a integralidade do cuidado.

Grossi \& Kobayashi (2013, p. 758) discutiram limitações associadas a atividades online, como acesso à internet, falta de tempo, dificuldade para interação e comunicação, sendo estas, limitações que transcendem a pandemia. Rocha et al. (2017, p.171) atribuem a visita domiciliar como uma ferramenta para aproximação entre os sujeitos, além de contribuir para assistência integral do indivíduo, à medida que os aspectos para além da saúde física são avaliados. Na tentativa de amenizar o impacto dessa lacuna, os acadêmicos apresentavam-se com a câmera ligada. Além disso, na primeira reunião, os participantes foram convidados a relatarem a história de seus descendentes, tal como apresentá-los por meio de fotografias, a fim de construir uma relação entre os universitários e os familiares assistidos. A construção de uma identidade visual ao projeto também foi utilizada como ferramenta para familiarizar e aclimatar os sujeitos, conforme proposto na Figura 1.

Paralelo as reuniões, postagens e vídeos informativos e educacionais foram disponibilizados por meio do Facebook como ferramenta de psicoeducação. A configuração dos perfis relacionados ao diálogo em saúde nas redes sociais são um fenômeno de comunicação que merece atenção além da esfera da rede social, devido ao seu alcance entre o público (Escoda et al., 2020). Por isso, a página do Facebook Educar Falciforme foi criada com o objetivo de expandir o conhecimento sobre a DF e ajudar as famílias do município de Divinópolis, Minas Gerais, através de postagens informativas e educativas sobre assuntos relacionados ao tema durante a pandemia de COVID 19. A primeira postagem ocorreu em março de 2020 e promoveu informação de educação em saúde, priorizando o autocuidado em relação à doença, o qual é preconizado pelo Manual de 
Educação em Saúde - Autocuidado em Doença Falciforme (BRASIL. Ministério da Saúde, 2008). Visou-se familiarizar as pessoas com DF à patologia, fortalecendo o estímulo à inclusão social, às suas necessidades como cidadãos, no âmbito do trabalho, da educação e do desenvolvimento social. Esses aspectos contribuem, de forma decisiva para a qualidade de vida dessas pessoas. Promover e informar sobre o acesso aos programas de promoção à saúde é fundamental para a integralidade na atenção em saúde e muito contribuirá para superar barreiras como as distâncias dos centros de referência e dos hemocentros (BRASIL. Ministério da Saúde, 2015).

Em meados de Junho/2020, a página possuía um total de 28 participantes ativos, compostos por $75 \%$ do gênero feminino e $25 \%$ de perfis do gênero masculino. No período de 1 ano e 2 meses foram realizadas 38 postagens, sendo 55,26\% imagens educativas, $26,31 \%$ informativas, $7,90 \%$ informativas/educativas e $10,53 \%$ vídeos educativos. Neste período a página recebeu 16 comentários, sendo $81,25 \%$ do gênero feminino e $18,75 \%$ do gênero masculino; 202 reações com uma média de 5,31 para cada postagem, sendo $85,64 \%$ do gênero feminino e $14,36 \%$ do gênero masculino; $2,63 \%$ das postagens foram compartilhadas. O mês mais ativo foi Abril/2020 com 34,21\% das postagens, 35,64\% das reações, $56,25 \%$ dos comentários e 100\% dos compartilhamentos. Esses achados sugerem que o Facebook pode desempenhar um papel importante na facilitação do engajamento público nas atividades de promoção da saúde (Bender et al., 2011).

Verifica-se que a promoção de educação em saúde através da página Educar Falciforme criada durante a pandemia de COVID 19 obteve êxito em seus objetivos propostos alcançando 71,43\% dos participantes da página, com a participação de $85 \%$ do gênero feminino e $15 \%$ do gênero masculino. No entanto, a super-representação das mulheres e a sub-representação correspondente de homens comprometeram a representatividade da amostra. Os dados ressaltam o gênero feminino predomina nos âmbitos relacionados à saúde da mulher e de seus filhos, sendo essas, na maioria das vezes, chefes de família e responsáveis pela educação e cuidados essenciais. Tal barreira também pode ser significativa para estudos futuros que tentam usar o recrutamento baseado no Facebook para pesquisas.

Os achados deste estudo apoiam a utilidade das plataformas de mídia social como uma ferramenta para recrutar de forma eficiente e eficaz um determinado público, especialmente durante crises de saúde globais ou regionais em rápida evolução, como a COVID-19, quando outros métodos de recrutamento não são mais seguros, práticos ou viáveis.

Figura 1: Identidade visual do projeto Educar Falciforme.

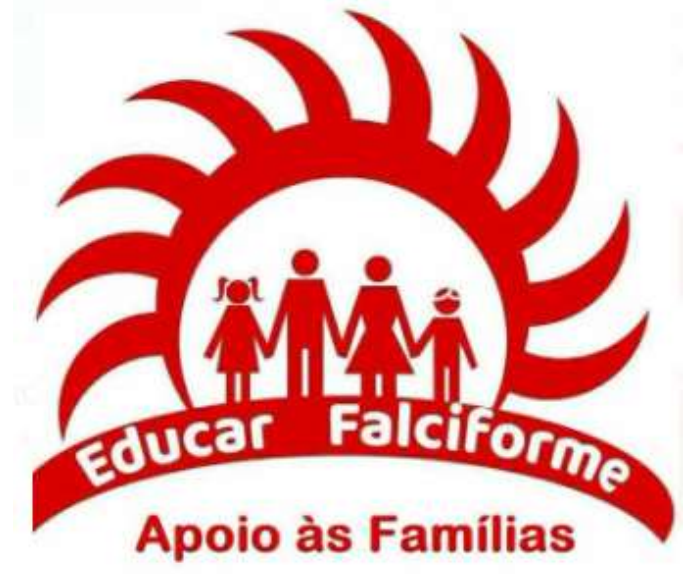

Fonte: Acervo pessoal.

\section{Considerações Finais}

Devido à atual crise sanitária mundial e da necessidade do isolamento social como medida de prevenção da COVID19, a tecnologia tem se mostrado uma grande aliada em todas as áreas e principalmente na saúde, possibilitando o cuidado, a 
vigilância, a educação em saúde, o ensino e a pesquisa. Ademais, as ações remotas através das redes sociais possibilitaram o fortalecimento dos vínculos entre os acadêmicos da extensão universitária, famílias e profissionais participantes do grupo.

Desse modo, é importante ressaltar que a DF faz parte do grupo de risco para COVID-19 por ser uma doença crônica com eminente risco de potencialização de agravos causada pelo coronavírus, o que requer acompanhamento e cuidado contínuo. Para tanto, o Programa de Extensão Educar Falciforme visa permanecer as atividades com as famílias em formato online enquanto necessário o for, devido às medidas de distanciamento social, além de estender as práticas educativas virtuais aos profissionais da Atenção Primária à Saúde, com o objetivo de otimizar os cuidados destinados à população com DF.

Portanto, a extensão universitária possibilitou aos discentes um maior contato com a realidade das famílias de crianças e adolescentes com DF e propiciou educação em saúde e apoio psicoemocional para todos os indivíduos contemplados, contribuindo para o alcance da integralidade do cuidado.

\section{Referências}

Almeida, R. A. de, \& Beretta, A. L. R. Z. (2017). Sickle Cell Disease and laboratory approach: a brief literature review. Revista Brasileira de Análises Clínicas, 49(2), 131-134. 10.21877/2448-3877.201700530

Bender, J. L., Jimenez-Marroquin, M. C., \& Jadad, A. R. (2011). Seeking support on facebook: A content analysis of breast cancer groups. Journal of Medical Internet Research, 13(1), 1-12. 10.2196/jmir.1560

Brasil. Ministério da Saúde. (2015). Doença Falciforme: Diretrizes Básicas da Linha de Cuidado. In Brazilia, DF (Vol. 1). https://bvsms.saude.gov.br/bvs/publicacoes/doenca_falciforme_diretrizes_basicas_linha_cuidado.pdf

Brasil. Ministério da Saúde. (2008). Manual de Educação em Saúde: Autocuidado na Doença Falciforme (Vol. 1). https://bvsms.saude.gov.br/bvs/publicacoes/manual_educacao_saude_volume1.pdf

Brasil. Ministério da Saúde. Secretaria de Vigilância em Saúde. Departamento de Análise em Saúde e Doenças não Transmissíveis (2021). Guia de vigilância epidemiológica Emergência de saúde pública de Importância nacional pela Doença pelo coronavírus 2019 - covid-19. https://www.conasems.org.br/wpcontent/uploads/2021/03/Guia-de-vigila\%CC\%82ncia-epidemiolo\%CC\%81gica-da-covid_19_15.03_2021.pdf

Cançado, R. D., \& Jesus, J. A. (2007). A doença falciforme no Brasil. Revista Brasileira de Hematologia e Hemoterapia, 29(3), 204-206. 10.1590/S151684842007000300002

Caprini, F. R., Motta, A. B., Caprini, F. R., \& Motta, A. B. (2020). The psychological impact on family caregivers of children and adolescents with sickle cell anemia. Estudos de Psicologia (Campinas), 38(1), 1-13. 10.1590/1982-0275202138e190168

Chakravorty, S., \& Williams, T. N. (2015). Sickle cell disease: A neglected chronic disease of increasing global health importance. Archives of Disease in Childhood, 100(1), 48-53. 10.1136/archdischild-2013-303773

Daltro, M. R., Bahiana, E., Medicina, D., Pública, S., \& Faria, A. A. De. (2019). Relato de experiência: Uma narrativa científica pós modernidade, 19 (1), 223-237. 10.12957/epp.2019.43015

Elia, G. M., Angel, A., Regacini, R., Nais, R. P., Santos, A. R. A. dos, Vieira, P. P. M. G., \& Braga, J. A. P. (2021). Acute chest syndrome and COVID-19 in sickle cell disease pediatric patients. Hematology, Transfusion and Cell Therapy, 43(1), 104-108. 10.1016/j.htct.2020.11.005

Escoda, A. P., Narros, C. J., Espinosa, M. P. L., \& Pedrero-Esteban, L. M. (2020). Social Networks' Engagement During the COVID-19 Pandemic in Spain: Health Media vs. Healthcare Professionals. International Journal of Environmental Research and Public Health, 17(14), 5261. doi.org/10.3390/ijerph17145261

Estrela, F. M., da Cruz, M. A., Gomes, N. P., da Silva Oliveira, M. A., dos Santos Santos, R., Magalhães, J. R. F., \& de Almeida, L. C. G. (2020). COVID-19 and chronic diseases: Impacts and developments before the pandemic. Revista Baiana de Enfermagem, 34(1), 1-7. 10.18471/rbe.v34.36559

Figueiredo, S. V., Lima, L. A., SIlva, D. P. B., Oliveira, R. de M. C., Santos, M. P., \& Gomes, I. L. V. (2018). Importância das orientações em saúde para familiares de crianças com doença falciforme. Revista Brasileira de Enfermagem, 71(6), 3150-3158. 10.1590/0034-7167-2017-0806

Gesteira, E. C. R., Szylit, R., Santos, M. R., Farialchikawa, C. R., Oliveira, P. P., \& Silveira, E. A. (2020). Manejo familiar de crianças que vivenciam a doença falciforme: um estudo qualitativo. Rev Bras Enferm, 73(4), 1-9. 10.1590/0034-7167-2019-0521

Giovelli, L. L., Danieli, K., Bortolotto, A. N., Mastella, A. K., Prior, M. P., Castro, S. M., Arrua, C. J., \& Silva, J. E. P. da. (2011). Estudo comparativo entre metodologias de triagem para detecção de hemoglobina S em bancos de sangue. Jornal Brasileiro de Patologia e Medicina Laboratorial, 47(2), 137-140. 10.1590/S1676-24442011000200007

Grossi, M. G., \& Kobayashi, R. M. (2013). Building a virtual environment for distance learning: An in-service educational strategy. Revista Da Escola de Enfermagem, 47(3), 756-760. 10.1590/S0080-623420130000300033

Gustin, C., Pimentel, W., Sarsur, M., \& Dadalto, L. (2021). A bioética da intervenção como possibilidade de inclusão social de pacientes com doença falciforme em tempos de COVID-19. Revista Latinoamericana de Bioética, 20(2), 41-53. 10.18359/rlbi.4703 
Research, Society and Development, v. 10, n. 11, e416101119590, 2021

(CC BY 4.0) | ISSN 2525-3409 | DOI: http://dx.doi.org/10.33448/rsd-v10i11.19590

Mélo, C. B., Farias, G. D., Nunes, V. R. R., Andrade, T. S. A. B. de, \& Piagge, C. S. L. D. (2021). A extensão universitária no Brasil e seus desafios durante a pandemia da COVID-19. Research, Society and Development, 10(3), 1-12. 10.33448/rsd-v10i3.12991

Piel, F.B., \& Steinberg, M.H., R. D. C. (2017). Sickle cell disease. N Engl J Med, 376(16), 1561-1573. 10.1056/NEJMra1510865

Pinotti, C. (2020). Extensão universitária:cenário e financiamento. Research, Society and Development, 9(5), 1-13. 10.33448/rsd-v9i5.3150

Ramos, E. M. B., Ramos, P. R. B., Carvalho, M. H. P. de, Silva, D. M. da, \& Júnior Dutra, P. H. de F. (2020). Portadores da doença falciforme: reflexos da história da população negra no acesso à saúde. Revista Eletrônica de Comunicação, Informação, Inovação e Saúde, 14(3), 681-691. 10.29397/reciis.v14i3.1882

Rocha, K.B., Conz, J., Barcinski, M., Paiva, D., Pizzinato, A. (2017). A visita domiciliar no contexto da saúde: Uma revisão de literatura. Sociedade Portuguesa de Psicologia Da Saúde, 18(1), 170-185. 10.15309/17psd180115

Rosenfeld, L. G., Bacal, N. S., Cuder, M. A. M., da Silva, A. G., Machado, Í. E., Pereira, C. A., de Souza, M. de F. M., \& Malta, D. C. (2019). Prevalence of hemoglobinopathies in the brazilian adult population: National health survey 2014-2015. Revista Brasileira de Epidemiologia, 22(2), 1-9. 10.1590/1980549720190007

Roy, N. B. A., Telfer, P., Eleftheriou, P., de la Fuente, J., Drasar, E., Shah, F., Roberts, D., Atoyebi, W., Trompeter, S., Layton, D. M., Lugthart, S., StuartSmith, S., Chakravorty, S., Wright, J., Porter, J., Inusa, B., \& Howard, J. (2020). Protecting vulnerable patients with inherited anaemias from unnecessary death during the COVID-19 pandemic. British Journal of Haematology, 189(4), 635-639. 10.1111/bjh.16687

Santos, J. H. de S., Rocha, B. F., \& Passaglio, K. T. (2016). Extensão Universitária E Formação No Ensino Superior. Revista Brasileira De Extensão Universitária, 7(1), 23-28. 10.36661/2358-0399.2016v7i1.3087

Souza, J. B. de, \& Carvalho, T. dos S. (2021). Formação de professores para o uso de tecnologias digitais: Um relato de experiência no Colégio Estadual Professora Luzia Carvalho Silva. Research, Society and Development, 10(4), 1-16. 10.33448/rsd-v10i4.14156

Vilela, T. de S., Braga, J. A. P., \& Loggetto, S. R. (2021). Hemoglobinopathy and pediatrics in the time of COVID-19. Hematology, Transfusion and Cell Therapy, 43(1), 87-100. 10.1016/j.htct.2020.11.002

Zago, M. A., \& Pinto, A. C. S. (2007). Fisiopatologia das doenças falciformes: Da mutação genética à insuficiência de múltiplos órgãos. Revista Brasileira de Hematologia e Hemoterapia, 29(3), 207-214. 10.1590/S1516-84842007000300003 